Article

\title{
Levinas, Simmel, and the Ethical Significance of Money
}

\section{Christopher Buckman}

Department of Philosophy, Auburn University, Auburn, AL 36849, USA; ccb0040@auburn.edu

Received: 30 November 2018; Accepted: 20 December 2018; Published: 22 December 2018

\begin{abstract}
An examination of Emmanuel Levinas' writings on money reveals his distance from-and indebtedness to-a philosophical predecessor, Georg Simmel. Levinas and Simmel share a phenomenological approach to analyses of the proximity of the stranger, the importance of the face, and the interruption of the dyadic relationship by the third. Money is closely linked to the conception of totality because money is the medium that compares heterogeneous values. Levinas goes beyond Simmel in positing an ethical relation to money permitting transcendence.
\end{abstract}

Keywords: Levinas; Simmel; money; ethics; totality

An examination of Emmanuel Levinas' writings on money reveals his distance from-and indebtedness to-a philosophical predecessor, Georg Simmel. While not commonly understood as central to his project, Levinas' comments on the ethical meaning of money recur throughout his work, not excepting Totality and Infinity. "Equality among persons", he writes there, "means nothing of itself; it has an economic meaning and presupposes money, and already rests on justice-which, when well-ordered, begins with the Other" (Levinas 1969, p. 72). Money and justice, uneasily correlated from the start, permit the establishment of political equality, which only takes on its moral value as their consequence. The circulation of goods as merchandise, and consequently the need for a universal medium of exchange, become an existential possibility with the primordial alienation of property, the gift to the other motivated by generosity; “This original dispossession conditions the subsequent dispossession by money" (Levinas 1969, p. 76). Levinas' first explicit criticism of Heidegger in Section I comes in this context, shifting attention from the sphere of production to circulation, distribution, and consumption: "The relationship between the same and the other, my welcoming of the other, is the ultimate fact, and in it the things figure not as what one builds but as what one gives" (Levinas 1969, p. 77). To be alive to the other is to give what one has, but the capacity to give equals the capacity to sell. Money, like language, holds phenomenological primacy in the structure of ethical relations.

It is clear that money figures meaningfully, if not prominently, in the central argument of Levinas' main work. But to chart the full significance of money in Levinas' thought, we must look especially to two detailed studies bookending his most productive period. The essay "The $I$ and the Totality", first published in 1954, concludes with a few pages on the subject of money in its relation to the ethical. The late essay "Sociality and Money", written in 1987 by invitation of the Banques d'Épargne Belges, extends and transforms his early ideas about money in the light of his ultimate philosophical viewpoint (Levinas 2007, p. 206).

Adequate understanding of Levinas' statements on money also requires comparison to the best-known philosophical treatise on the topic to emerge in the preceding century, Georg Simmel's Philosophy of Money, published in 1900. Reading the two theories in relation inevitably brings about the recognition of deeper similarities between the two thinkers. Both Simmel and Levinas take up many of the same themes: the grip of totality, the place of the stranger in moral life, the role of the third, 
the significance of the face in relating to the other. I shall suggest that Levinas receives but transforms these structures to bestow on them an ethical import missing in Simmel's purely aesthetic descriptions.

It is historically fitting that Levinas, along with Simmel's students Georg Lukács and Ernst Bloch, should be heir to Simmel's scholarship. When seventeen-year-old Levinas arrived at the University of Strasbourg in 1923 to study philosophy, only five years had passed since the transition of the German institution into a French one. Simmel had served as professor and chair of philosophy at Strasbourg from 1914 to 1918. Previously excluded from a position suiting his stature due to antisemitism, he had been called to the post as part of an effort to build a liberal, cosmopolitan culture more agreeable to the sentiments of the local population than the German-nationalist outlook dominant since the close of the Franco-Prussian War (Craig 1984, pp. 191-92). Levinas surely would have been introduced to Simmel's thought by the Alsatian professors permitted to stay on the faculty, as well as by other citizens of Strasbourg: Simmel had given well-attended public lectures on sociology. There is no evidence available to reconstruct precisely how, and to what extent, Simmel's ideas were transmitted to Levinas, but we can point to clear parallels in their work.

To begin with, both thinkers employ a phenomenological method. Levinas' Husserlian credentials are well known. He studied under Husserl at Freiburg and wrote his first major work on eidetic intuition. Despite critiquing phenomenological intentionality as incapable of capturing the relation to the infinite demanded by ethics, Levinas continued to recognize the preeminence of phenomenology as a basis for objective science, offering perceptive phenomenological descriptions in his own works. Simmel's connection to phenomenology is less obvious. The first volume of Husserl's Logical Investigations only appeared in 1900, the same year as Simmel's fully mature Philosophy of Money, so we know that Simmel did not appropriate Husserlian phenomenology in any direct sense. Yet it has been cogently argued that Simmel's mode of analysis can only be understood as utilizing eidetic intuition. Gary Backhaus painstakingly demonstrates that the most common criticisms of Simmel一that his analyses are ahistorical and that he fails to give the statistical evidence needed to ground empirical generalizations-evaporate when it is seen that Simmel is consciously and explicitly describing transcendental meanings, registering a material a priori, and not pretending to strive for a purely inductive social science (Backhaus 1998, p. 2180). The same can be said for the accusation, repeated even by Simmel translator David Frisby, that Simmel relies too heavily on arguments from analogy, which in truth signal the grasping of shared essences (Frisby 1990, p. 5). "Not only did Simmel intend an eidetic science", Backhaus writes, "but he indeed successfully registered the eidetic principle inherent to specific forms" (Backhaus 1998, p. 275). Among these forms are associations such as marriages and business partnerships, of which Simmel gives phenomenological descriptions based in the method of free variation. Other scholars have taken note of this fact. Early English-language commentator Nicholas J. Spykman, for instance, remarked in 1925 on the "phenomenological" character of Simmel's technique, apparently using the word in its strict sense (Spykman 1964, p. 214; see also Weinstein and Weinstein 1993, p. 21).

Beyond the kinship in method, parallels in the content of Levinas' and Simmel's analyses are especially striking. First, Levinas takes up the theme of regard for the stranger, echoing Simmel's relatively well-known analysis of the stranger as a social form. It is not surprising that Levinas should consider this figure, part of the Deuteronomic trio of the stranger, the orphan, and the widow-a favorite reference. But a comparison between the two writers on this social type is instructive.

In an essay included in his 1908 collection Soziologie, Simmel stresses a dual relationship between an individual in a social group and the stranger (der Fremde) inhabiting that group's territory: a simultaneous nearness and remoteness. The stranger embodies the synthesis of rootedness and pure "wandering" (Simmel 1971, p. 143). The stranger is not completely disconnected from the world of the group; as Simmel delightfully observes, "The inhabitants of Sirius are not exactly strangers to us". One becomes a stranger by inducing a feeling of strangeness, an awareness of her distance, her not-belonging to the unity of the social structure. One might say that the stranger escapes reduction to the social totality. But she does not entirely escape; we understand her as bearing general 
characteristics common to humanity as a whole. These attributes cannot form the basis of a warm personal connection in the same way the particularities of the residents signify their similarity and bind them in community, but they do establish a common humanity. The stranger holds a dedicated place of otherness within the social structure, an "inorganically appended" element which nevertheless counts as an "organic member" (Simmel 1971, p. 149). At the forefront of Simmel's essay stands the paradox of proximity occasioned by the stranger: "The distance within this relation indicates that one who is close by is remote, but his strangeness indicates that one who is remote is near" (Simmel 1971, p. 143).

A paradoxical remoteness-in-proximity also marks the stranger in Levinas' writing, showcasing the metaphysical relation at the heart of his ethics. I meet the stranger face to face, an embodied presence requiring attention and care. At the same time, the distance to the stranger is unbridgeable because the stranger is not fully available in the way most beings are: "He is not wholly in my site" (Levinas 1969, p. 39). The remoteness of the stranger frustrates my power, my ability to control the things at my disposal, which the stranger manages to escape. The stranger as a social figure typifies the transcendent other- the other of metaphysical desire.

Levinas explicitly denies that the relation to other qua stranger takes its meaning from the stranger's belonging to the human group, an enclosing circle larger than the social circle of the community: "I, who have no concept in common with the Stranger, am, like him, without genus" (Levinas 1969, p. 39). It is easy to think of this sentence as a rebuke of Simmel's flattening of the stranger into a placeholder for humanity in general, the outer limit of the same. Levinas and Simmel both describe a relation in which the other exceeds the sameness of unity, but with one crucial difference. While Levinas resists incorporating the other into a higher-order system, Simmel posits a larger totality, a new social whole in which the stranger and the social group are both already situated: the stranger is only such as a member of my species, as the human animal, standing to me in a relation "based on merely human similarities", as Simmel writes, but on similarities nonetheless (Simmel 1971, p. 148). This contrast between Levinas and Simmel will be seen to mark a recurring pattern. The ethical significance of the resistance to totality demands, in Levinas' view, that the other stands uncomprehended, "absolved" while in relation. At just the points in Simmel's analyses at which he approaches the recognition of a transcendent other, he reincorporates the distant relatum into a larger whole or credits it a merely aesthetic significance.

An example of the latter is Simmel's exploration of the face as the limit of social totality in his 1901 essay "The Aesthetic Significance of the Face". The role of the face in Levinas' philosophy will be familiar. On one hand, the face of the other person is present, skin and eyes bared, the paradigmatic locus of embodiment. On the other hand, the face in its full sense "is neither seen nor touched" (Levinas 1969, p. 194); as we have already observed of the stranger, the face "resists my powers" (Levinas 1969, p. 197), meaning my spontaneous powers of world-building. For Levinas the face signifies the instant of ethical relation, the presentation of the other irreducible to, in Kantian terms, categories of the understanding. The other shines forth from the face in uniqueness.

Here, again, the Simmelian analysis features areas of overlap and divergence. Simmel also assigns the face primacy in interpersonal relations. "The face", art historian Margaret Werth explains in recounting Simmel's interpretation, "is important to our knowledge and experience of individuality, and offers the visual form of persisting inwardness as well as of shifting immediacy" (Werth 2006, p. 84). The otherness-in-presence of the stranger, as for Levinas, appears in the face in concentrated form. Human life consists in organizing the complexity and chaos of experience into meaningful unities. Religion and morality, Simmel believes, are two approaches toward effecting this synthesis (Simmel 1959a, p. 257). The aesthetic impulse is a third, and here the face has place of honor. Simmel perceptively describes how the custom of clothing the body up to the neck, which he oddly associates with Christianity, sets off the face as the corporeal site of the presentation of interiority. Thus framed, facial features combine to express "the highest degree of this kind of inner unity" (Simmel 1959b, p. 276). The most minute alteration of one of the elements transforms the meaning of the whole, 
demonstrating the intimate, finely-tuned interdependence of the parts. The eye, Simmel tells us, focuses the expressive powers of the face:

The eye epitomizes the achievement of the face in mirroring the soul. At the same time, it accomplishes its finest, purely formal end as the interpreter of mere appearance, which knows no going back to any pure intellectuality behind the appearance. It is precisely this achievement with which the eye, like the face generally, gives us the intimation, indeed the guarantee, that the artistic problems of pure perception and of the pure, sensory image of things-if perfectly solved - would lead to the solution of those other problems which involve the soul and appearance. Appearance would then become the veiling and unveiling of the soul (Simmel 1959b, p. 281).

Simmel struggles here in his bid to overcome dualism, denying a dichotomy between spirit and flesh, yet hindered by the stale language of "body" and "soul", sliding from the aesthetics of embodiment back into the physiognomy of nineteenth-century idealism. But we see an effort emerging to sketch out a merger of the terms, an incarnate spirituality worked out more satisfactorily by Simmel's friend Henri Bergson. Simmel is only able to voice the intention to come to an understanding of transcendence transpiring in the body, and, specifically, in the face. The problem remains imperfectly solved. Levinas, in contrast, follows Bergson in purging from his thought more thoroughly the residue of dualism. The face discloses the other not because the eyes mirror the soul, but because the face displays a presence unmastered by my organizing syntheses.

Simmel, as will Levinas, builds up his phenomenological description of sociation as a developing series: the isolated individual, the dyad, and finally the entrance of the third. The lone individual has primacy in the order of analysis, though not, as we shall see, in Simmel's social ontology. At the core of his account of the individual is a conception of freedom, which counts not as "solipsistic existence but as sociological action" (Simmel 1950, p. 121). The isolated individual gains meaning not from her positive existence but from relation to the missing others, "whether as lingering-on of past relations, as anticipation of future contacts, as nostalgia, or as an intentional turning away from society" (Simmel 1950, p. 121). Turning away, from society as a whole or from a specific relation or obligation, represents one side of freedom, an overcoming of limits, "a continuous process of liberation" (Simmel 1950, p. 121). At the same time, freedom means control, impressing one's will on objective relations already bound up with the existence of others. We savor freedom as power. Simmel's interpretation of the isolated individual already includes the social dimensions of liberation and domination.

Because isolation presupposes society, the fundamental form of sociation is the dyad (Zweierverbindung), the cleaving of the one to the other. The distinctiveness of this structure stems from its utter dependence on both individuals: if one term exits, the relation ceases to exist. The "group" of two is rarely perceived as having autonomy above and beyond its members (Simmel 1950, p. 123). Intimacy, attentiveness to the particular rather than the universal, is the hallmark of the dyad. The paradigm of it is monogamous marriage: "The fact that male and female strive after their mutual union is the foremost example or primordial image of a dualism which stamps our life contents generally" (Simmel 1950, p. 128). The one cannot, being opposite, fuse with the other; yet the impulse to do so organizes meaning and action. Simmel continues:

The fact that, in any real and absolute sense, the "I" can not seize the "not-I", is felt nowhere more deeply than here, where their mutual supplementation and fusion seem to be the very reason for the opposites to exist at all. Passion seeks to tear down the borders of the ego and to absorb "I" and "thou" in one another. But it is not they which become a unit: rather, a new unit emerges, the child (Simmel 1950, p. 128).

Marriage thereby consummates the erotic intimacy of the dyad and transitions it into a new form: the triad. More complex configurations of mediation, interrelation, and transcendence become possible with the third, whether in the form of the child or any other social kind. The third appears in 
many guises-the invader, the nonpartisan, the arbitrator. She can be the tertius gaudens who benefits from conflict or she may cultivate discontent in order to divide and conquer. An unbroken vista of social possibilities opens up with the admittance of the third. Simmel's careful analysis of these forms constitutes one of his most esteemed contributions to sociological theory.

Levinas also describes "sociality" within the framework of the one, the other, and the third (Levinas 2007, p. 206). A notable difference emerges right away in the treatment of the solitary individual. For Simmel, the individual cannot really exist alone; isolation is always defined by the lack of the others. Levinas rejects this claim outright. The I of separation, atheism, and enjoyment, Levinas repeatedly insists, is self-sufficient, not unstable due to any lack or structural deficiency. The I at its origin is not "sociological", he explicitly states; the thinking which already posits the other as existing in absence conceives of the other ontologically as a "copy" of the same, primed for appropriation under a higher genus (Levinas 1969, pp. 120-21). Whereas Simmel posits nostalgia as a primary mode of being of the separate individual, Levinas warns that nostalgia does "not even suspect what the veritably other is" (Levinas 1969, p. 33). While consistent with the existence of the sociological individual as one possibility of consciousness, Levinas maps out a more primordial order invisible to Simmel's analysis. Levinas' view also conflicts with Simmel's assertion that the freedom of the individual consists in evading or dominating others as obstacles. "The Other", Levinas writes, "is not initially a fact, is not an obstacle, does not threaten me with death; he is desired in my shame... And if the other can invest me and invest my freedom, of itself arbitrary, this is in the last analysis because I can feel myself to be the other of the other" (Levinas 1969, p. 84). Aimed chiefly at Hegel's master-slave dialectic, these lines also have bearing on Simmel's characterization of freedom as emancipation and control.

This divergence in the first stage of the analysis conditions Levinas' description of the relation of the one to the other, which hardly needs elaboration here. Instead of resulting from loneliness or gregariousness, and far from ratifying a law of domination, the relation to the other is initiated from the outside, by the other. The passivity of welcoming characterizes it. The genuine transcendence of the other, portrayed by the face, establishes an asymmetrical relationship which refrains from turning the other into a second version of the self. All of this opens a higher dimension lacking in Simmel's leveling, symmetrical description of the dyad.

When the third appears in Totality and Infinity, it is in relation to discourse, to language, which makes possible the face-to-face exchange with the other. Due to the transparency and universality of meaning established in the back-and-forth between the one and the other, the relation is open from the beginning to inspection by the third:

Language as the presence of the face does not invite complicity with the preferred being, the self-sufficient "I-Thou" forgetful of the universe; in its frankness it refuses the clandestinity of love, where it loses it frankness and meaning and turns into laughter or cooing. The third party looks at me in the eyes of the other-language is justice. It is not that first there would be the face, and then the being it manifests or expresses would concern himself with justice; the epiphany of the face qua face opens humanity (Levinas 1969, p. 213).

The third, in the first instance, neither results (the child) nor interferes (the intruder), but is brought along with the face met in discourse. Beneath and before the anthropological role of the third in articulating a dynamic social structure, the third conveys the presence of all the others, of humanity, as primordial and ineffable as the original other of the face-to-face.

But we should not think, because of these evident discrepancies, that the Levinasian and Simmelian descriptions are entirely dissimilar. There are extensive parallels, not least of which being the overall framework of the analysis, advancing from solitude to the other to the third. In Levinas' account of the third in the early essay "The I and the Totality", as Robert Bernasconi points out, "the third party seems virtually indistinguishable from the third person", very much, in other words, like Simmel's multivalent sociological type (Bernasconi 1999, pp. 77-78). In "The I and the Totality", Levinas introduces the third explicitly to argue that love-immersion in the dyad-cannot 
institute justice or spiritual existence (Levinas 1998, p. 17). Lost in intimacy, the one and the other are surprised by the third, who "disturbs" them, bringing larger society to bear on the totalized world (Levinas 1998, p. 19). "The closed society is the couple", but it is an erotic society, not a linguistic society (Levinas 1998, p. 21). Just as in Simmel, and against the dyadic I-Thou of Buber, the interwoven complexities of justice and dialogue presuppose the third. But the third's primary mode of presence is economic, as a worker who has created the things now liable to appropriation by violence or "gold" (Levinas 1998, p. 30). Simmel's society of others, beginning with the third, constitutes a vaster totality accessible through money. We see a similar structure emerging in Levinas.

The conception of totality, contrasted by Levinas with infinity, finding its quintessential expression for Simmel in the meaning of money, underpins the points of contact between the two thinkers. Along with the Spencerian synthetic philosophy, Neo-Kantianism had decisive influence on Simmel's development, and the imprint of Kant's conception of "community", the interrelation of the totality of objects, is discernible in Simmel's thought, informing his self-proclaimed "relativism". Kant argued in the Third Analogy of Experience of the Critique of Pure Reason that the experience of temporally coexistent, spatially distinct objects requires an a priori concept of the understanding holding all objects to condition each other in a relation of reciprocal influence. Hence, the totality of objects signifies not merely static coexistence, but mutual codetermination. This structure of reciprocally-determining dynamic totality appears in Simmel as the guiding thread of sociation, value, and, more broadly, being. It becomes, in Simmel's words, "a regulative world principle that everything interacts in some way with everything else, that between every point in the world and every other force permanently moving relationships exist" (Quoted in Frisby 1984, p. 50). These linked relays are mutually, fluidly co-governing and condition the epistemic structure, instituting the inner articulation of meaning and the conditions of truth. As Spykman observes, "The totality of our theoretic knowledge would then be no more true than that the totality of matter is heavy" (Spykman 1964, p. 7). Since every point in the structure dynamically interrelates with every other, every truth-content bears privilege in granting access to the whole system. Hence Simmel's oft-quoted dictum, "In each of life's details, the totality of its meaning" (Simmel 1990, p. 55).

Money represents the totality in concentrated, inverted form, exchangeable with any value, transferable by nature- the abstracted essence of flux. Simmel writes:

There is no more striking symbol of the completely dynamic character of the world than that of money ... Money is nothing but the vehicle for a movement in which everything else which is not in motion is completely extinguished. It is, as it were, an actus purus; it lives in continuous self-alienation from any given point and thus forms the counterpart and direct negation of all being in itself (Simmel 1990, p. 511).

Blasphemous, but suggestive: Just as God contains no non-being in the mode of potentiality, not only is there nothing money cannot do, there is nothing money does not do. Being has, for us, a teleological structure, but the substitution of means for ends in modernity becomes so thoroughgoing, so complete, that money—pure substitutability—exhausts both ends and means. The style of modern life thereby gives rise to the blasé attitude, which "experiences all things as being of an equally dull and grey hue" (Simmel 1990, p. 256). The blasé person merely accelerates the pace of life in a vain attempt to counteract the leveling of its contents, which, with recognition of their dissipation into the determining structure, become perfectly fungible. Totality swallows all.

Totality and money would be linked in the mind of any careful reader of Simmel, so it should be no surprise that Levinas concludes his essay on totality with a section on money. First, he touches on the danger posed by totality: that the system devours everything within it; codetermination turns violent. As Simmel's blasé person recognizes, the identity of everything with everything else follows from the closure of totality. But Levinas promises escape in transcendence, through discourse with a genuine interlocutor, through the face: “The face breaks the system" (Levinas 1998, p. 34). Only the other is self-identical, non-fungible. The relation to a self-determining other cracks open history for 
the inflow of justice, coming from its outside, having "no other object but economic equality", not to obliterate totality but to rectify it (Levinas 1998, p. 36).

Levinas then proceeds to discuss the ethical significance of money, stressing the social stability entailed by its use. An established community must exist to support the development of a generally accepted medium of exchange. In this respect, the circulation of money implies what Simmel would call "objective culture", a shared, enduring background of accreted meanings against which we live our lives. But money poses risks. People can be bought and sold, through bribes or as slaves. Nevertheless, despite the dangers inherent in the intermixture of humanity and merchandise, money is a prerequisite of justice, because in its absence an offence against a person can only be repaid in an ever-continuing chain of vengeance, or by unearned and unwise forgiveness, which only invites a new offence. While the principle of lex talionis holds good, conversion of the debt into monetary form breaks the cycle of violence, allowing the restoration of peace. "It is certainly quite shocking", Levinas writes, "to see in the quantification of man one of the essential conditions of justice. But can we conceive of a justice without quantity and without reparation?" (Levinas 1998, p. 38).

We need money because we demand reparation, and the value of reparation is decided by the value of a human being, which can be rendered as a magnitude. Here is one last echo of the Simmelian analysis. In his study of the ancient Germanic practice of wergild, Simmel traces the origin of money-value to the debt incurred in the killing of a person. Nobles of increasing rank were assigned exponentially increasing restitution values. "This tendency not only makes money the measure of man, but it also makes man the measure of the value of money" (Simmel 1990, p. 356). The differential value of the whole money-system would then be pinned to the "valuation of offence" (Simmel 1990, p. 356). Just as for Levinas in his early essay, money and justice are deeply intertwined and can be traced back to the value placed on a human being.

In Levinas' later thought attention to the meaning of money for totality and transcendence supplants the focus on reparation. We have seen that in Totality and Infinity money figures as the complement to things-as-merchandise, a mode of objectivity made possible by primordial generosity, which releases the environment from the enjoying self. The question becomes one of maintaining non-totalizing relationships between economically linked individuals. "Sociality and Money" continues in this vein but is couched in the language of Otherwise than Being or Beyond Essence. The essay is structured according to a distinction between "inter-estedness" (intér-essement) and "dis-inter-estedness" (dis-intér-essement), terms playing on varieties of existence transpiring between and across being (Levinas 2007, p. 206, footnote 2). Levinas proposes that the relation between individuals established by money, as buyers, sellers, and producers, "without prior acquaintance", can nevertheless facilitate the face-to-face discourse of the ethical relation (Levinas 2007 , p. 203). Without the presentation of the physical body, without spatial proximity, even absent any communicative situation, the commercial web carries a "sociality that already runs through it" (Levinas 2007, p. 203). Gone from the analysis is the dubiously indispensable wergild. Money now takes on a positive ethical significance.

But Levinas still recognizes its dangers. Money renders heterogeneous orders homogeneous through comparison and totalization. Worse, when utilized to unreflectingly procure goods for personal enjoyment and survival, it has the power to suppress the happiness of others for the sake of one's own being, in which every individual is inter-ested. Self-interest weaponizes money for the "seizure and takeover of being by beings", for ontological consumption (Levinas 2007, p. 204). Indifference to the other, through competition and jealousy, becomes struggle and exploitation. Levinas warns:

Hard univocity of inter-estedness that has become hatred: imitation between men, rivalry and competition to the point of the cruelty and tyranny of money and the bloody violence of war. Moreover, homogenization by money assimilates human services, labor, to things in wages and forgets the dead labor in these objects; henceforth, all value is recognized by 
means of the interestedness of need and can be appropriated in the act of purchase (Levinas 2007, p. 204).

Submerged in inter-estedness, the mindless consumer relates to products merely as objects of enjoyment, not as creations of other human beings. She willfully disconnects herself from the network of persons implicit in the money economy, ravenously maximizing pleasure, mutating into the callous rational agent of the economists. Money intensifies and empowers egoism.

A loftier relation to money is possible. The totality of the money economy constitutes a circuit in which members "do not exhaust themselves" (Levinas 2007, p. 205). Self-perpetuating, encroaching being, associated with Heidegger's Dasein, does not define humanity because one can sacrifice oneself, ceding place in being to the stranger, a proof of dis-inter-estedness. At this point in the essay Levinas recapitulates the analysis of the stranger from Totality and Infinity, describing the other's proximity as "axiology of the beyond being, axiology of transcendence" (Levinas 2007, p. 205). He then reintroduces the third to show that the dyadic relation to the stranger fails to do justice to the rest of humanity. For this we need political and economic institutions. We need money. But money, when kept in its proper place as a reservoir of value held back for use in cases of unexpected hardship or urgent need, no longer drives gluttony. It elevates generosity by answering to a wider range of needs than any specific goods. Money endows charity and invests kindness. Here, the analysis matches up perfectly with that of "The I and the Totality". When used for the wrong ends, selfishly, money invites evil; but its use for good is always a step in the direction of economic justice, which gives money its primary meaning (Burggraeve 1995, p. 13).

While the Simmelian note of wergild falls out of Levinas' later work, a trace of Simmel's social theory appears in the form of the stranger and the third, not to mention the description of the levelling effects on values caused by reduction to a universal medium of exchange. This is indicative of a deeper engagement with Simmel's thought running throughout Levinas' work. It is impossible to say which resemblances are fortuitous, which are rooted in direct inspiration, and which are intended as knowing allusion. But the correspondences are well-defined, and more work might be done in such areas as comparing the two philosophers' use of the term "adventure" or reading Simmel's analysis of empty space alongside Levinas' description of the il $\mathrm{y}$ a. Along with the usual figures such as Hegel, Buber, and Heidegger, Simmel should be considered one of Levinas' important interlocutors.

Funding: This research received no external funding.

Acknowledgments: This research stems in part from discussions at a 2017 National Endowment for the Humanities summer seminar, "Morality, Justice and the Political", held at the University at Buffalo. I am indebted to Richard Cohen, James McLachlan, and Jolanta Saldukaityte, especially for her thoughts on the Stranger. Any views, findings, conclusions, or recommendations expressed in this publication do not necessarily reflect those of the National Endowment for the Humanities.

Conflicts of Interest: The author declares no conflict of interest.

\section{References}

Backhaus, Gary. 1998. Georg Simmel as an Eidetic Social Scientist. Sociological Theory 16: 260-81. [CrossRef]

Bernasconi, Robert. 1999. The Third Party: Levinas on the Intersection of the Ethical and the Political. Journal for the British Society for Phenomenology 30: 76-87. [CrossRef]

Burggraeve, Roger. 1995. The Ethical Meaning of Money in the Thought of Emmanuel Levinas. Ethical Perspectives 2: 11-16. [CrossRef]

Craig, John E. 1984. Scholarship and Nation Building: The Universities of Strasbourg and Alsatian Society 1870-1939. Chicago: The University of Chicago Press.

Frisby, David. 1984. Georg Simmel. New York: Tavistock Publications.

Frisby, David. 1990. Introduction to the Translation. In The Philosophy of Money, 2nd ed. Edited by David Frisby. New York: Routledge, pp. 1-49.

Levinas, Emmanuel. 1969. Totality and Infinity: An Essay on Exteriority. Translated by Alphonso Lingis. Pittsburgh: Duquesne University Press. 
Levinas, Emmanuel. 1998. Entre Nous: On Thinking-Of-The-Other. Translated by Michael B. Smith, and Barbara Harshav. New York: Columbia University Press.

Levinas, Emmanuel. 2007. Sociality and Money. Business Ethics: A European Review 16: 203-7. [CrossRef]

Simmel, Georg. 1950. Quantitative Aspects of the Group. In The Sociology of Georg Simmel. Kurt H. WolffGlencoe: The Free Press, pp. 87-177.

Simmel, Georg. 1959a. The Adventure. In Georg Simmel, 1858-1918. Edited by Kurt H. Wolff. Columbus: The Ohio State University Press, pp. 243-58.

Simmel, Georg. 1959b. The Aesthetic Significance of the Face. In Georg Simmel, 1858-1918. Edited by Kurt H. Wolff. Columbus: The Ohio State University Press, pp. 276-81.

Simmel, Georg. 1971. The Stranger. In Georg Simmel on Individuality and Social Forms. Edited by Donald N. Levine. Chicago: The University of Chicago Press, pp. 143-49.

Simmel, Georg. 1990. The Philosophy of Money, 2nd ed. Translated by Tom Bottomore, and David Frisby. New York: Routledge.

Spykman, Nicholas J. 1964. The Social Theory of Georg Simmel. New York: Russell \& Russell. Weinstein, Deena, and Michael A. Weinstein. 1993. Postmodern(ized) Simmel. New York: Routledge. Werth, Margaret. 2006. Modernity and the Face. Intermédialités 8: 83-102. [CrossRef]

(c) 2018 by the author. Licensee MDPI, Basel, Switzerland. This article is an open access article distributed under the terms and conditions of the Creative Commons Attribution (CC BY) license (http:/ / creativecommons.org/licenses/by/4.0/). 